\title{
IS PAGET'S DISEASE OF THE NIPPLE PRIMARY OR SECONDARY TO CANCER OF THE UNDERLYING BREAST?
}

\author{
ALSON R. KILGORE, M.D. \\ Instructor in Surgery, University of California Medical School and Member of \\ Surgical Staff, St. Luke's Hospital \\ SAN FRANCISCO
}

When Sir James Paget wrote, in 1874, his classical account of the disease which bears his name, he described the condition clinically, rather than pathologically. Based on his own observation of fifteen cases, he outlined the course of a moist, red eczema followed by ulceration of the nipple and areola, upon which cancer of the underlying breast constantly developed. In each of his fifteen cases the breast cancer made its appearance within a year, or at most two years, after the onset of the nipple eczema.

The fact that Paget's description did not include that of the histopathology of the disease has been responsible for much of the confusion which has existed, and still exists, in the minds of surgeons and pathologists over the exact nature of Paget's disease. Without the evidence of microscopic study, it is impossible, many times, to distinguish between true Paget's disease and secondary ulceration of the skin over an advancing cancer. Exactly this mistake has been made by no less an authority than Handley, ${ }^{1}$ in a recent communication. Many surgeons consider Paget's disease to be any scabbing or eczema or ulceration of the nipple which follows the clinical course described by Paget. In a well known laboratory, it is considered that "there is no such thing-it either is, or it is not, cancer." And in still a third laboratory, squamous-ce!l cancer of the nipple is classified with Paget's disease.

\section{ESSENTIAL FEATURES}

It will make for accuracy in discussion of the subject to limit the term "Paget's disease" to conditions presenting the striking, unique and constant histopathology first described by Butlin ${ }^{2}$ and Thin, ${ }^{3}$ and later confirmed by many others. There are three essential features:

(a) Epidermal Hypertrophy.-The skin epithelium in the affected area (before the stage of ulceration, and ahead of the advancing margin, after ulceration begins) is increased to two or three times its normal

1. Handley: Brit. J. Surg. 7:183, 1919.

2. Butlin: Med. Chir. Tr., London 9:107, 1876.

3. Thin: Tr. Path. Soc., London 32:218, 1881. 
thickness. The papillary bodies not only extend deeper, but are thicker, encroaching from the side on the connective tissue papillae to such an extent as finally almost to obliterate them. These changes are very sharply marked off from the normal epithelium at the edge of the lesion.

(b) Subepidermal Round-Cell Infiltration.--A very constant feature is a marked infiltration of the connective tissue under the epidermis with lymphocytes, plasma cells and occasional polymorphonuclear leukocytes. The infiltration is usually sharply limited to the affected area and is responsible for the sensation, obtained by palpation, as of a coin buried beneath the epidermis.

(c) The So-Called "Paget's Cells."-These are large edematous cells in the epithelium, which become vacuolated, with shrunken, pyknotic nuclei, giving the appearance of punched-out holes in the epithelium. They appear first typically in the middle layers of the epithe'ium and extend downward and upward. Often nearly the whole papillary body is occupied by these cells.

These Paget's cells have been the subject of much dispute. They are, of course, strictly speaking, not Paget's cells at all, inasmuch as Paget made no histologic description; but, since they form a striking and characteristic feature of the disease known by his name, they are commonly called Paget's cells.

\section{VARIOUS THEORIES}

They have been considered, first, to harbor a specific parasite, the cause of the disease ; then to be simply degenerated epithelial cells; and, finally, by some authors, to be single-cell metastases of cancer. The earlier parasitic theory has been discarded with later careful microscopic studies under higher magnification. The theory that Paget's cells are actually cancer cells was advanced by Jacobaeus, ${ }^{4}$ who believed he had found a direct connection between them and the cells of underlying breast cancer. This work has not been adequately confirmed, while von Winiwarter ${ }^{5}$ and others have traced much more convincingly all stages between the prickle cells of the epithelium and Paget's cells. They do not resemble either morphologically or in behavior the cells of cancer arising either in the skin or in the breast gland, and the best opinion is that they are degenerated skin cells.

These, or similar cells, are not found exclusively in Paget's disease, though they are unusual except in this condition. We have found, for example, a group of cells morphologically identical with Paget's

4. Jacobaeus: Virchows Arch. f. Path. Anat. 178:124, 1904.

5. Von Winiwarter: Arch. f. Dermat. u. Syph. 85:239, 1907. 
cells in the epithelium near the edge of a squamous-cell cancer of the lip, though the other typical features of I'aget's disease were lacking.

Furthermore, it is very easy to mistake for Paget's cells actual cancer cells invading the cpidermis from an approaching cancer. The appearance in cross-section of a strand of cancer cells incaling the skin epithelium from below suggests very strongly the vacuolated, edematous appearance of a true I'aget's cell. Sekiguchi "has obviously fallen into such error in interpreting some of his cases-an error against which the student should be easily warned by an observation of the frequency of just such appearances when cancer approaches the skin, often associated with the ustal subepidermal cell infiltration seen in the various

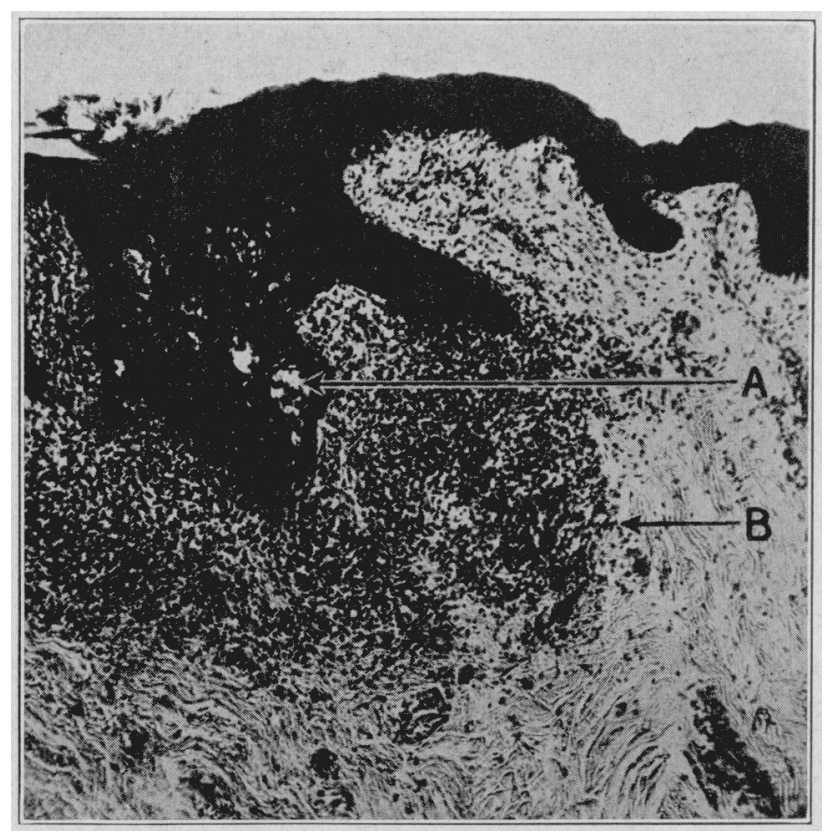

Fig. 1.- Farliest case of Paget's clisease. Process limited to small areas of surface epithelinm: $f$, nests of Paget's cells in hypertrophied epithelium; $B$, sharply limited zone of subepiclermal-cell infiltration.

stages of ulceration over cancer, and with the well known epithelial hypertrophy also common in this process.; Seliguchi is the most recent representative of the school holding that Paget's discase is itself malignant, drawing from his study the conclusion that "Paget's disease is primary carcinoma of the orifices of the lactiferous ducts or (in extramammary regions) the sudoriferous ducts." This view, we believe, is

6. Sekiguchi: Ann. Surg. 65:175, 1917.

7. Kilgore: J. Cancer Res. 5:291 (Ju1y) 1920. 
untenable. It has often been pointed out by others that the disease exists clinically for years in other regions of the body, in some cases without ever being associated with cancer of any form, in others being followed by squamous-cell cancer. Furthermore, an unusually early case which we have had opportunity to study (Case 1) shows the typical histopathology of Paget's disease, but as yet absolutely no involvement of the ducts. It seems to us very clearly demonstrated that Paget's disease is not itself a form of cancer, nor are true Paget's cells ever migrated cancer cells.

While, therefore, cells like Paget's cells may occur under other co:1ditions, the specific combination of epithelial hypertrophy, subepithelial round-cell infiltration and Paget's cells is so striking and so constant as to call for definite recognition; and it will remove much of the uncertainty which still exists in our knowledge of the condition to limit the term "Paget's disease" to lesions presenting this typical pathologic condition.

RELATION OF PAGET'S DISEASE TO CANCER OF THE BREAST

Is Paget's disease primary or secondary to the cancer of the breast which so constantly accompanies it?

Paget's original conception was that the eczema of the nipple precedes and is undoubtedly in some way responsible for the later development of cancer in the underlying breast. Since his time, authors have been, for the most part, sharply divided into two schools, one represented by Jacobaeus, ${ }^{4}$ who agrees with Paget; the other, represented by Schambacher, ${ }^{8}$ who asserts that the breast cancer is always present before the development of the Paget's diseast, explaining the existence of the nipple condition for a long period before the cancer becomes apparent, on the well known possibility of a slow-growing scirrhous cancer remaining small for years and hence overlooked.

A consideration of well known facts makes the latter view untenable. While Paget's disease may sometimes be secondary to the cancer, events cannot always follow this sequence, for two reasons: First, typical Paget's disease occurs in regions remote from the breast and never associated with malignant disease of any kind (the illustration showing the pathology of the condition in Ewing's ${ }^{9}$ text is taken from a case occurring on the buttock). Second, cases of true Paget's disease, clinically and pathologically, have been found in the nipple and areola over a breast containing absolutely no evidence of cancer. Such cases will be reported later in this paper.

8. Schambacher: Deutsch. Ztschr. f. Chir. 80:332, 1905.

9. Ewing: Neoplastic Diseases, Philadelphia, W. B. Saunders Company, 1919, p. 808. 
It is much more difficult to prove that Paget's disease may sometimes be secondary to breast cancer. Certainly this sequence is unusual, for the skin involvement over an adrancing breast cancer usually presents a histologic picture entirely different from that of l'aget's disease. But in a histologic study of 500 breast cancers which I made, one case showed the typical pathologic condition of Paget's clisease with a clinical history stggesting that the cancer had long antedated the nipple condition (Case + ).

I feel sure, therefore, from a careful study of the cases to be reported here, that Pagret's disease. while usually primary, may also be secondary to cancer. The principal reason for the disagreement which has existed over this point lies undoubtedly in the rarity of the

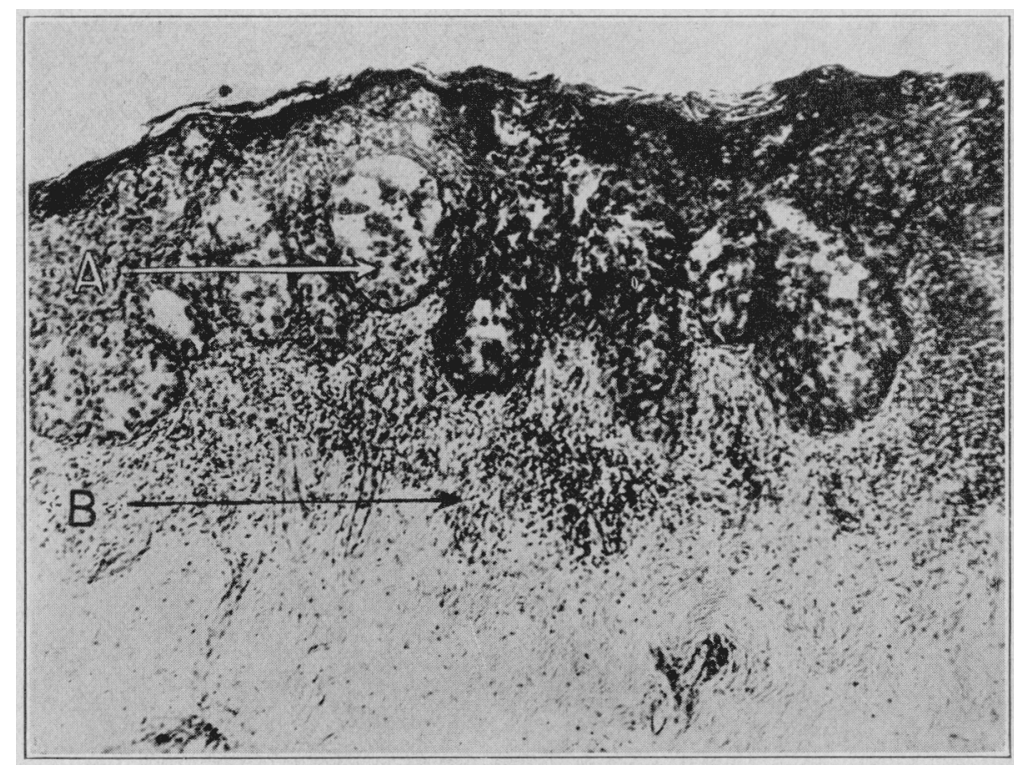

Fig. 2.- More adranced stage of surface condition: A, nests of Paget's cells in hypertrophied cpithclium. Note the widening of the down-growing epithelial processes obliterating the connective tissue papillary bodies. $B$, zone of roundcell infiltration.

condition, most of the important contributions since l'aget's time having been based on studies of one or two cases.

Through the courtesy of Dr. Joseph C. Bloodgood, it has been my privilege to study the material in the surgical pathology laboratory of the Johns Hopkins Hospital. The following case reports comprise all the undoubted cases of true Paget's clisease found in a total of more than 1.500 cases of manmary disease (four cases, representing less than one third of 1 per cent. of pathologic conditions of the breast). 
CASE 1 (Path. No. 24410).-History.-A woman, white, aged 35, who had two children, aged 10 and 7, and in whom there had been no abnormality of lactation, gave a history of slight moisture and scabbing of the left nipple for eighteen months.

Operation.-Complete breast and axilla operation was performed by $\mathrm{Dr}$. W. A. Fisher.

Gross Specimen: This shows over about half of the nipple a smoothness and thickening of the epidermis which is also seen on section. Palpation gives a definite sensation of induration under this area. The change, however, is very slight.

Microscopic Examination: This area shows the typical histology of early Paget's disease with epithelial hypertrophy, Paget's cells and subepithelial roundcell infiltration (Fig. 1). Careful search through the gross specimen fails to reveal any evidence of tumor of any kind-only a few dilated ducts in the nipple zone. Microscopic search through blocks cut from various areas of the breast shows only these dilated ducts with some desquamated cells, but with nothing to suggest the picture of duct adenocarcinoma of the type usually seen with Paget's disease. Axillary lymph nodes show only endothelial hyperplasia.

Comment.-This is a case clinically and pathologically typical of Paget's disease-certainly in one of the earliest stages in which the condition has been observed. A thorough search through the breast failed to reveal any sign of gross or microscopic malignancy, either in the form of definite tumor, epithelial invasion of connective tissue, or hyperplasia of the duct epithelium. The conclusion is necessary therefore that in this instance Paget's disease occurred before the development of cancer in the breast.

CASE 2 (Path. No. 21819).-History.-A woman, white, single, aged 74, had had crusting of both nipples as long as she could remember-little warty crusts which would slowly form and then drop off, being renewed usually about once a year. A year ago she struck the left nipple with her hand, and it bled for a few days, so much that she wore a cloth over it. A crust then formed as usual but had been growing larger for four or five months, and the nipple had disappeared, leaving in the center of its former site the crust surrounded by an elevated zone, red and eczematous, which the patient had first noticed five months ago.

Operation.-Complete excision of the left breast with a zone of skin was made. There was no axillary dissection.

Examination.-Gross Specimen (Specimen sent by Dr. A. F. Robinson): On section through the nipple, the red area is seen to be very superficial with no gross cancer beneath. In the position of the nipple there is a circumscribed area about the size of the end of the little finger which gives one the impression of a depressed nipple, and beneath this a fan-shaped zone of breast stroma mixed with fat. There are no dilated ducts, no cysts, and no gross evidence of tumor.

Microscopic Findings: There is no evidence of cancer in the stroma. The ducts deep in the breast, however, are plugged with proliferated cells, the morphology and staining reactions of which suggest the cells of duct cancer. The characteristic changes of Paget's disease are found in the epithelium of the areola (Fig. 2). In this instance, it was not possible to trace continuously the changes from the nipple to the deeper ducts mentioned above, though it is probable that if sections had originally been taken with this in view, such continuous changes could have been traced. 
Result.-The patient was well two years after operation; the condition of the opposite nipple being unchanged.

Comment.-This case, like Case 1, is typical Iaget's disease clinically and pathologically, and yet no delinite tumor existed in the breast, and not enough change in the deep duct epithelium was observed to make a positive diagnosis of malignancy. It must le considered, therefore, another case in evirlence that Paget's disease occurs primary to, or at least before the development of, mammary cancer.

Case 2 represents the second step in the development of cancer in the underlying breast from Paget's dicease, as the process has been con-

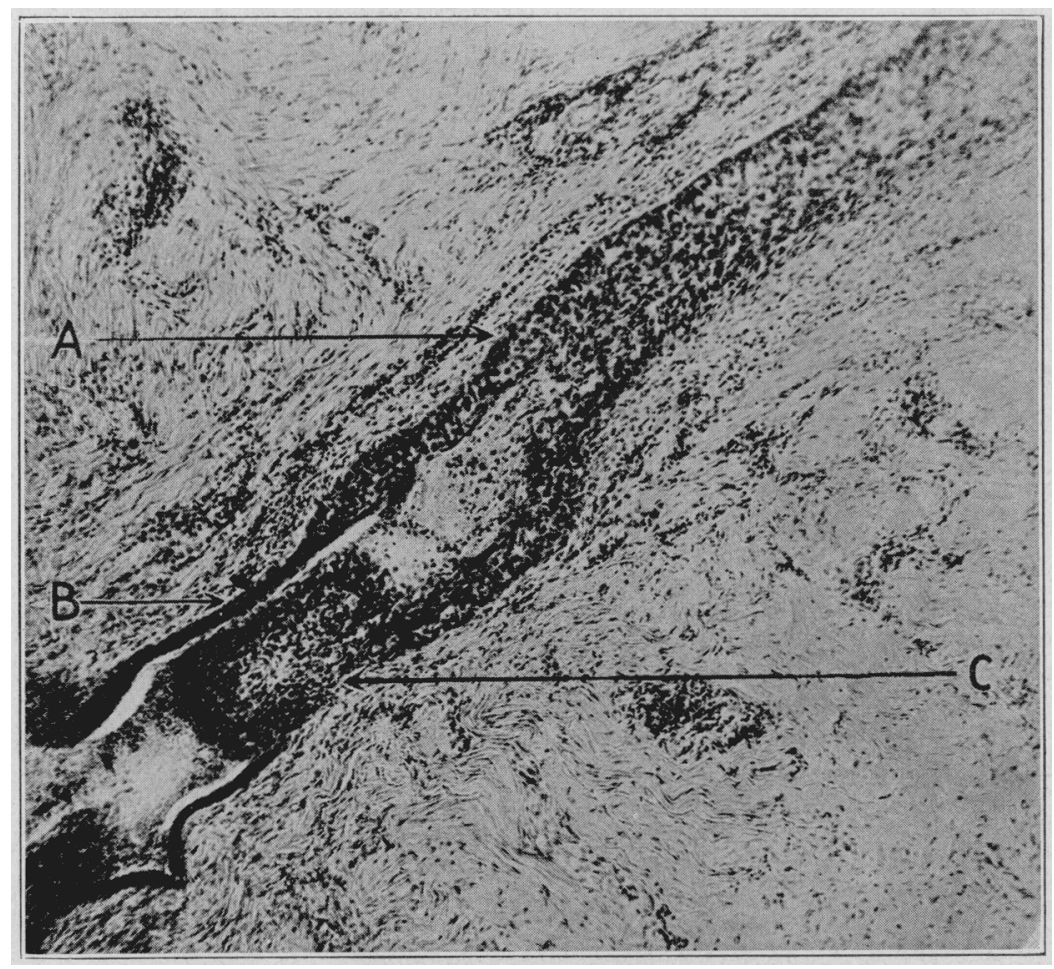

Fig. 3.-Transition in a duct between the extending disease $A$ and normal duct wall $B$. At $C$, the duct curves a little so that its roof was cut in the section, obscuring the transition point on one side.

ceived by Duhring and 11 ile ${ }^{10}$ and others. According to this view, the skin condition appears first (as in Case 1). The process then extends from the skin into the ducts in its second stage (Case 2), and finally, by excessive proliferation deep in the breast, the cells burst ont of the ducts, invading the connective tissue and forming cancer.

10. Duhring and Wile: $\triangle \mathrm{m}$ J. M. Se. 88:141, 1884 
This conception is probably not far from the truth. Certainly the process can be shown to extend from the Paget's disease at the surface, down progressively along the ducts (Case 4), and it resembles in many ways the process at the surface. More than one observer has been able to see the point at which the proliferated cells plugging the ducts apparently break through the duct wall and invade the connective tissue (Jopson and Speese). ${ }^{11}$ It seems unlikely, however, that a change to malignancy on the part of the epithelial cells occurs on account of over-filling of the ducts and rupture of their walls, but rather that the latter occur on account of malignant properties already developed in the cells. We have, as yet, no good explanation of when or how the change from benignancy to malignancy occurs, unless it be at the moment when the proliferative process in the ducts begins at their orifices, and that this process is from its inception a duct adenocarcinoma.

Case 2 presents clinically interesting points in the long duration of the condition of scabbing of both nipples, and the development of Paget's disease in one after trauma.

CASF 3 (Path. No, 21055).-History.-A woman, white, aged 72, single, had eight months before examination, first noticed itching around one nipple with some surrounding redness which gradually spread. There had been some mucous discharge from the nipple. A scab formed over the nipple and gradually replaced it.

Examination.-This scal) with the areola around it was redder than normal and when this reddened area was picked up, it was felt to be distinctly infiltrated. No nodule could be felt in the breast.

Operation.-The breast was excised; axillary dissection was not performed.

Gross Pathology: The nipple was replaced by a scabbed ulcer with a surrounding zone of redness. On section, the epithelium in this zone was visibly thickened and there was definite induration under it. No tumor was found in the breast-only a few dilated ducts.

Microscopic Findings: The nipple changes presented the typical histology of Paget's disease, while the dilated ducts seen in the gross specimen presented microscopically the picture seen in the ducts of duct cancer (such as those in Case 2); but in this case also they were isolated and formed no definite tumor (Fig. 4).

Comment.-In this case again, true Paget's disease of the nipple had antedated any definite tumor in the breast, and the reasonable presumption is that it had antedated the early changes seen in the ducts. The process is similar in its stage of development to that observed in Case 2.

CASE 4 (Path. No. 22629).-History.-A widow, colored, aged 43; who had had six children-the youngest child being 7 years old, and two miscarriages, had two years before, received a bruise in the upper, outer quadrant of the left breast. Six months later she first noticed a lump at the site of injury. Three months ago, that is, fifteen months after she first noticed the lump, it broke through the skin spontaneously. She had noticed gradually increasing retraction of the nipple for several months and, one month ago, for the first time, she noticed ulceration at the nipple.

11. Jopson and Speese: Ann. Surg. 62:212, 1915. 
Opcration-A complete operation for cancer was performed.

Gross Specimen: This shows the nipple replaced by an ulcer, and the areola at the site of the nipple retractel. On section, the ulcerated cancer in the upper outer quadrant is at least $4 \mathrm{~cm}$. from the nipple, but extending from the nipple in the direction of the tumor are seen dilated ducts filled with yellowish material. The suggestion in the gross specimen is that the nipple ulceration has been caused by the discharge of irritating material from these ducts.

Microscopic Findings: The epithelium at the margin of the nipple ulcer shows the typical pathologic condition of Paget's disease, and the month of one duct is found plugged with proliferated cells resemlling those of duct cancer. The plug of cells extends clown the duct 2 or $3 \mathrm{~mm}$. and ends in an abrupt

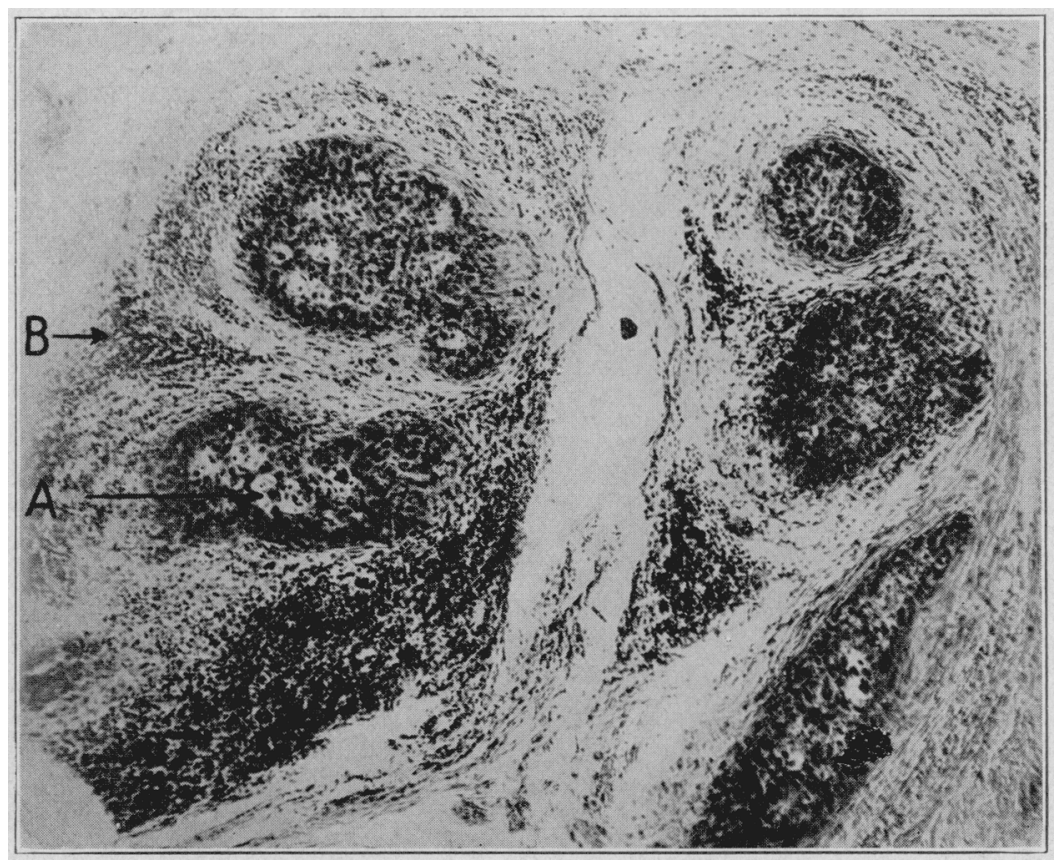

Fig. 4.-Process as it appears when it has extended to the deep ducts of the breast. The ducts are plugged with cells and present an appearance similar to that of duct cancer: $A$, vacuolated cells, resembling Paget's cells; $B$, zone of round-cell infiltration.

transition to apparently normal duct epithelium (Fig. 3). No other plugged ducts are found either in the nipple section or in blocks taken between this area and the tumor.

Commont.-In this case the tumor had been present at least fourteen months and had ulcerated through the overlying skin two months before the nipple ulceration was noticed. Either this was fauly observation on the part of the patient, or the cancer was present before the Paget's disease of the nipple. I do not believe the patient's observation was faulty for three reasons: (1) Her attention had been called to the nipple by its retraction, and ulceration would 
undoubtedly have been observed. (2) Experience shows that patients are quick to observe changes in the nipple. In a study of 500 breast cancers which $I^{7}$ have made, no nipple epithelial change was found pathologically which had not been observed by the patient as eczema or ulceration. (3) The pathologic condition of this specimen itself suggests that the Paget's disease is recent, for the characteristic proliferative changes in the ducts have progressed only 1 or 2 $\mathrm{mm}$. below the nipple epithelium.

I believe that the obvious inference is correct, namely, that the Paget's disease followed on a primary breast cancer, but I am not justified in making a positive commitment on the evidence of one case. My justification in thus reporting and discussing a single case presenting this sequence of cancer first, and Paget's disease second, rests on the rarity of the condition, but four instances of true Paget's disease having been found among 1,100 breast cancers observed during twenty-five years.

\section{OTHER NIPPLE LLCERS}

Ulceration of the nipple may be the first sign by which a deepar cancer manifests itself, a cancer which may not be found as a palpable tumor for months or years after the nipple change begins. The cancer may be so deep in the breast that excision of the nipple and surrounding zone of breast and skin would fail to include any of the cancer and so lead to erroneous diagnosis. This is illustrated by the case herewith reported:

Case 5 (Path. No. 7107, not true Paget's disease).-History.-A woman. white, aged 55, married, with four children, the youngest 27 , had had cracked nipples during her lactations years before. Eight months before examination the left nipple had shown slight erosion and had scabbed over, the scab falling off every few weeks. No tumor was felt in the breast. The record contained no description of the condition of the areola around the nipple.

Operation.-Excision of the nipple and zone of breast and skin was made.

Microscopic Examination: This showed only chronic and acute inflammation. No cancer was found.

Result.-Three years later this patient was operated on for an infiltrating cancer near the scar in the breast, and died one month later from cerebral metastases. There is no good reason to doubt that the cancer already existed at the time of the first operation, was the cause, and not the result, of the nipple condition, and would have been found on pathologic examination had the entire breast been removed.

Comment.-A case almost identical in its history with Case 5 has been reported by Martin, ${ }^{12}$ in which a woman, aged 61 , presented crusted nipples for one year. The nipple was excised and pathologic examination revealed only simple inflammatory changes, which were mistakenly diagnosed "Paget's disease." Two years later, the patient returned. Examination reveaied a hard, irregular mass beneath the scar in the breast. It proved to be scirrhous cancer which had already metastasized to the axilla.

It seems to me that the lesson in Case $\mathbf{5}$ and of Martin's case is perfectly clear, namely, that any persistent eczema or ulceration of the nipple, whether

12. Martin: Ann. Surg. 64:725, 1916. 
true Paget's disease or not, requires, for the patient's safety, excision of the entire breast, not of the nipple alone.

\section{SUM MARY}

1. From the point of view of intensive study of the condition, the term "Paget's disease" should be limited to those lesions presenting the typical histology: $(a)$ epithelial hypertrophy; $(b)$ subepithelial round-cell infiltration; (c) Paget's cells.

2. All the cases of Paget's disease reported, however, as well as Case 5 and Martin's case (not true Paget's disease), emphasize the importance of removing the entire breast for any chronic, persisting nipple eczema or ulcer, regardless of the apparent presence or absence clinically of deeper breast changes. At operation, the decision for or against axillary dissection should depend, not on frozen section diagnosis of the nipple condition between true Paget's and other eczemas, but on the pathologic condition of the breast itself. The best procedure is amputation of the breast with a wide zone of skin, using the knife cautery in cutting across the lymphatics leading to the axilla, and proceeding immediately to the axillary dissection if any gross or frozen section evidence of cancer be found in the excised breast.

3. Three cases are reported demonstrating that Paget's disease is usually primary to cancer of the breast which has been found constantly in association with it. In one of these cases no change whatever had as yet occurred in the breast, and in two cases the early changes of what was probably duct carcinoma had begun when the breast was excised. A fourth case is reported in which all the evidence of history and pathology points to a reversal of this order, the cancer in the breast apparently originated first, and was followed by Paget's disease of the nipple. If the deductions in this case are correct then both schools in the controversy over the primary or secondary nature of Paget's disease have been right, since either order of events may occur.

4. Three stages in the process by which we believe cancer in the underlying breast develops from Paget's disease are illustrated by the various cases reported. Figure 1 shows the condition, limited to the surface; Figure 3 shows the condition in course of extension down the ducts from the nipple ${ }^{13}$ while Figure 4 is from a case in which the process had extended to the deep ducts. The picture resembles closely that of duct cancer. The final stage in which the cells plugging these deep lying ducts break out into the connective tissue and give rise to

13. Figure 3 is from the case in which deep cancer preceded the Paget's disease, but it is obvious that, once started, the Paget's disease is behaving as it usually does, extending down the ducts from the surface. 
scirrhous cancer was not found in this series but has been observed by other authors. ${ }^{11}$

391 Sutter Street.

NoTE.-A very complete bibliography of the literature of Paget's disease may be found in Deaver and McFarland: The Breast: Its Anomalies, Diseases and Their Treatment, Philadelphia, P. Blakiston's Son \& Co., 1916, p. 696. Since the publication of this bibliography, the following articles have appeared in addition to those already referred to:

Fowler: Tumors of the Areola and Nipple of the Breast, Med. Times 45: $195,1917$.

Burns: Paget's Disease and Carcinoma, Edinburgh M. J. 17:161, 1916.

Potter: Extramammary Paget's Disease, Jour. Cutan. Dis. incl. Syph. 34:306, 1916.

Harett: Case of Paget's Disease Treated by Radiotherapy, Jour. de radiol. et d'électrol., Par. 3:416, 1918-19.

Trimble: Eczema of the Nipples, Arch. Dermat. and Syph. 13:253, 1920.

Hartmann: Maladie de Paget, Rev. gén. de clin. et de thérap. 31: 581, 1917.

Thorndike: Dermatitis Simulating Paget's Disease, Boston M. and S. J. 77:122, 1917.

Brunsgaard: A case of Paget's Disease, For. med. Selsk. i Kristiania, 1916, p. 149. 